\title{
Holistic Evaluation of the Morbidity Due to Diabetes Mellitus Type 2 and Its Main Risk Factors in the State of San Luis Potosi, Mexico
}

\author{
Gaytán-Hernández Darío', Domínguez-Cortinas Gabriela², Mejía-Saavedra José de Jesús²*, \\ Márquez-Mireles Leonardo Ernesto ${ }^{3}$ \\ ${ }^{1}$ Faculty of Nursing, San Luis Potosí University, San Luis Potosí, México \\ ${ }^{2}$ Centre of Applied Research in Environment and Health, Faculty of Medicine, San Luis Potosí University, \\ San Luis Potosí, México \\ ${ }^{3}$ Faculty of Social Sciences, San Luis Potosí University, San Luis Potosí, México \\ Email: ijesus@uaslp.mx
}

Received 20 January 2015; accepted 9 February 2015; published 11 February 2015

Copyright (C) 2015 by authors and Scientific Research Publishing Inc.

This work is licensed under the Creative Commons Attribution International License (CC BY).

http://creativecommons.org/licenses/by/4.0/

(c) (i) Open Access

\begin{abstract}
Objective: To evaluate the morbidity due to diabetes mellitus type 2 within the State of San Luis Potosí, México, through a strong methodology, through which the multivariate relations were identified of the main social and environmental determiners in the disease, thus managing to quantify their respective levels of responsibility. Material and Methods: This evaluation began as a hypothesis of a multicasual theoretical model on diabetes mellitus and its main determining factors, which was analyzed through the application of multivariate exploratory statistical methodologies and confirmed as it is the case of the principal components analysis and the structural equation models. Results: Three components were extracted that explain the $96 \%$ of the total variance of the indicators; the main risk factors which were identified in the first component were, the use of the car, age, homes with TV use, urban life and feminine population; the indicators from the second and third component have little influence in the impact of the disease. Conclusions: the study shows the usefulness of the model for the analysis and prioritization of the environmental and social determiners of the disease, information that could sustain the design of public guidelines for the prevention and control of the analyzed disease.
\end{abstract}

\section{Keywords}

Diabetes Mellitus, Risk Factors, Multivariate Analysis

\footnotetext{
${ }^{*}$ Corresponding author.
}

How to cite this paper: Darío, G.-H., Gabriela, D.-C., de Jesús, M.-S.J. and Ernesto, M.-M.L. (2015) Holistic Evaluation of the Morbidity Due to Diabetes Mellitus Type 2 and Its Main Risk Factors in the State of San Luis Potosi, Mexico. Journal of Diabetes Mellitus, 5, 36-47. http://dx.doi.org/10.4236/jdm.2015.51005 


\section{Introduction}

Diabetes Mellitus is a chronic illness that appears when the pancreas does not produce sufficient insulin or when the body does not use it effectively [1]. Diabetes mellitus type 2 represents a serious health problem in the world; there were 387 million people with diabetes in 2014 and 4.9 million died due to this [2]; in Mexico there were 6.4 million adults with diabetes [3].

There are multiple risk factors that have been associated with diabetes, such as obesity, age, gender, belonging to a certain ethnic race, level of education, income, life conditions, access to health services and urbanization [4]. Also it is associated with factors as family history of diabetes, overweight, unhealthy diet and physical inactivity among others [5].

Several factors associated to diabetes mellitus type 2 have been analyzed (MDMT2); such is the case of an ecological study in obese adults older than 20 from 183 countries in which a positive relation between diabetes prevalence and a low income was found $(p=0.011)$ [6]. This was also confirmed by another transversal study in which it was identified a prevalence in diabetes mellitus type 2, 4.11 times higher in the group with a low income than that of a high income [7]. At the same time, it was found a higher prevalence of diabetes in people with a lower educational level $(p<0.001)$ [8]; as well as in people who belong in a 65 to 74 years old range ( $<$ 0.001) [9]. Deo and Col [10], found that the percentage of diabetics increased systematically with the age, finding a $1.69 \%$ of diabetics in the age group of 21 to 30 and a $20.9 \%$ in the 61 years and more group. Also, it is reported that obese people have a higher risk of suffering from diabetes than those at an average weight, basically women, (2.52 times) as for men (2.13) [11]. At the same time, it is described that some people with a family history of diabetes have a 2.9 times higher risk than those who do not have it and those with no physical activity have a 1.6 times higher risk than those that do some type of exercise [8]. On the other hand, it was identified that the residents of urban areas have more prevalence in diabetes than those on rural areas $(p<0.002)[6][9]$.

$\mathrm{Hu}$ and Col [12] reported that spending two or more hours per week watching television represents a risk factor to acquire diabetes. They also estimated that the risk increases 1.23 times for five hours and two times more for 40 hours $(\mathrm{p}=0.000)$.

The cited studies show an analysis of different risks factors and their relation with MDMT2 from a lineal perspective, without taking into account the possible multivariate relations, as a whole and simultaneously among them.

The present work proposes a robust methodology from of which we can achieve the integration of two multivariate methodologies: the principal components analysis components (PCA) to explore and identify latent variables and reduce the dimension of indicators; and a structural equation model (SEM) to confirm the identified structure through PCA as well organizes hierarchically the load of the factors upon MDMT2; which can generate integral information to support more effectively decision making, that incite in the decrease of this illness. Successful analysis have been carried out using this methodological tool in different fields of study as the confirmation of an explicative model of stress and its relation with psychosomatic symptoms trough structural equations [13], as well as to predict the well-being and the functional dependence of elderly people [14].

In accordance with the previous paragraph, the objective of the present research consists in evaluating MDMT2 in the State of San Luis Potosi, Mexico, with a methodological approach that would allow identifying the main social and environmental determiners of the illness, as well as their multivariate relations for the generation of integral proposals for prevention and effective actions directed to the solution of this health problem.

The basis for this study is the design of a theoretical model, of the main factors that determine MDMT2 (Figure 1); this model reflects the observable factors diversity and/or measurable as well as latent variables that are not observable nor measurable directly, due to the nature of the problem; it is necessary the use of specific multivariate techniques that would allow carrying out the analysis as the PCA and SEM.

\section{Material and Methods}

The State of San Luis Potosí is located in the North central region of the Mexican republic, it has a territorial span of 60,933 $\mathrm{km}^{2}$ and it is the Fifthteen State to its extension of the Mexican Republic. It has 58 counties with are distributed in four main geographical regions: Altiplano, Centre, Huasteca and Media [15].

A study was carried out to identify the main social and environmental determiners of the MDMT2 and their multivariate relations in the State. A theoretical multicasual model was designed of the MDMT2 and its main 


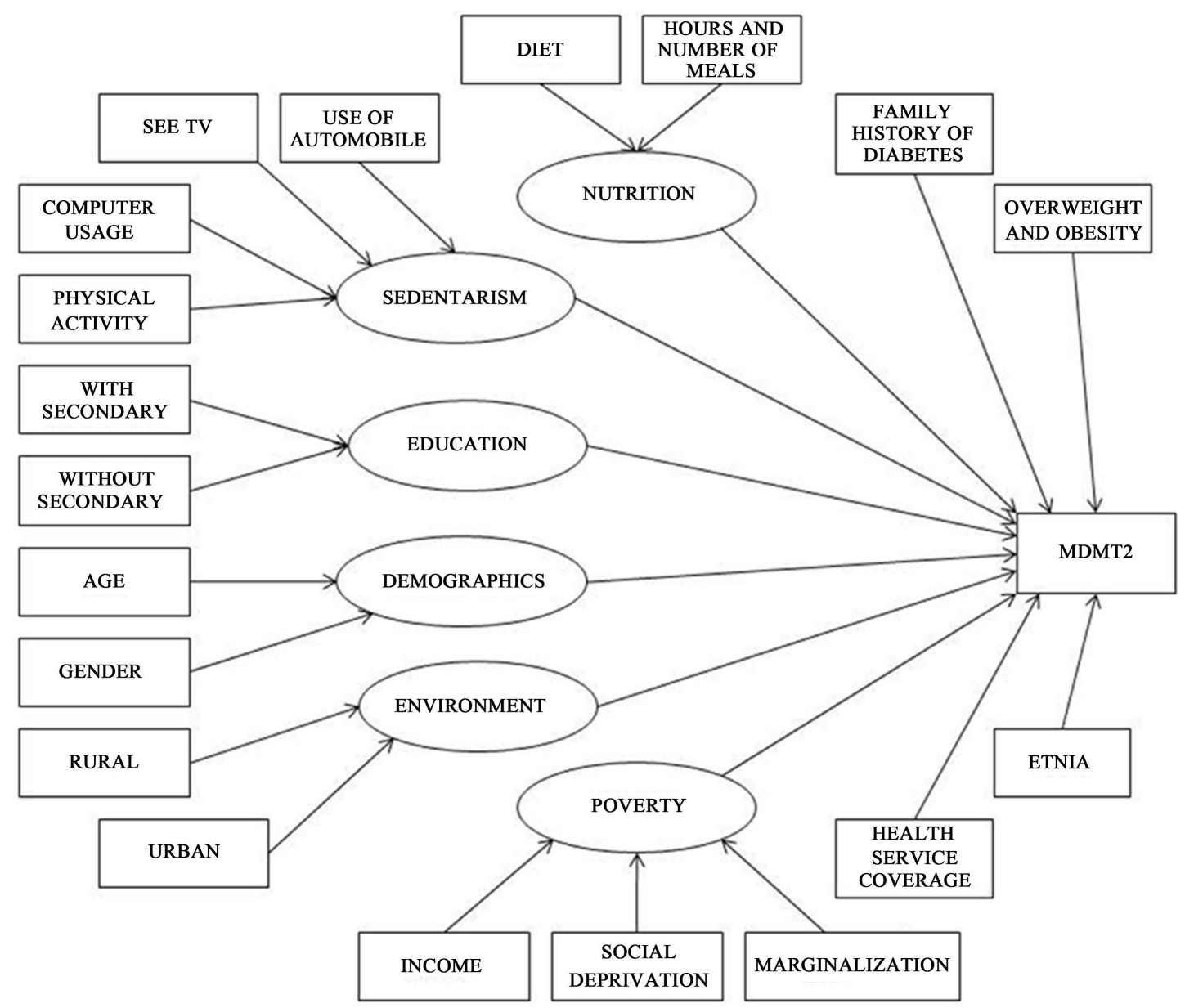

Figure 1. Theoretical model of determinants related to MDMT2.

determining factors based on the revision of the published studies that identify them as determinants of the illness (Figure 1), based on such scientific evidence and by availability of information, 17 indicators were selected (Table 1).

The population in the study was grouped in the following age ranges: 20 to 44,45 to 49,50 to 59,60 to 64,65 years and older; from the years 2005 and 2010, with data from the 58 counties that conform the State of San Luis Potosí.

\section{Statistical Analysis}

An outlook for the state was generated using the indicators signaled and the rates for MDMT2 by gender and age groups. An exploratory factorial analysis was used through the multivaried methodology for PCA in order to identify components or suppress variables (24).

The level of colineality among the indicators were evaluated through the determinant of the matrix of correlation, a value of the determinant nearing cero indicates the high existence of colineality. The Kaiser-Mayer-Olkin test was used to evaluate the adequacy of the sample, comparing the magnitudes of the observed correlation coefficients with magnitudes of partial correlation coefficients, this statistic takes values between 0 and 1 , values higher than 0.70 indicate that sample is adequate for utilize PCA [24]. Barlett's sphericity test, was used to reject the hypothesis that the correlations matrix and the identity matrix are equal [25]. The explained total variation table was generated to identify the number of components with eigen-values higher than 1 , as well as the percentage of the variance that they explain [24] [25]; and the sedimentation graph as a support to determine the optimum number of components to be included in the solution [24].

It was worked with a matrix of rotated components by the Varimax method in order to facilitate the interpreta- 
Table 1. List of used indicators.

\begin{tabular}{|c|c|c|}
\hline Code & Name & Description \\
\hline MDMT2 & Diabetes $^{*}$ & New cases in the year from diabetes mellitus type 2 [16]. \\
\hline IND1 & Female population $^{*}$ & Number of people from the female gender [17] [18]. \\
\hline IND2 & Male population ${ }^{*}$ & Number of people from the male gender [17] [18]. \\
\hline IND3 & Ages 20 to 44 & Number of people from 20 to 44 years of age [17] [18]. \\
\hline IND4 & Ages 45 to 49 & Number of people from 45 to 49 years of age [17] [18]. \\
\hline IND5 & Ages 50 to 59 & Number of people from 50 to 59 years of age [17] [18]. \\
\hline IND6 & Ages 60 to 64 & Number of people from 60 to 64 years of age [17] [18]. \\
\hline IND7 & Ages 65 and older & Number of people 65 and older [17] [18]. \\
\hline IND8 & Urban population $^{*}$ & Number of people in localities $\geq 2500$ habitants [17] [18]. \\
\hline IND9 & Rural population ${ }^{*}$ & Number of people in localities $<2500$ habitants [17] [18]. \\
\hline IND10 & Automobiles & Automobiles that are registered in circulation [19]. \\
\hline IND11 & Homes with TV & Number of houses with TV [17] [18]. \\
\hline IND12 & Without secondary ${ }^{*}$ & Population without secondary school [17] [18]. \\
\hline IND13 & Without health care ${ }^{*}$ & Population without right to public health care [20]. \\
\hline IND14 & Income $^{* *}$ & Population \% that earns up to 2 minimum wages [21] [22]. \\
\hline IND15 & Indigineou population ${ }^{*}$ & Population that speaks an indigenous tongue [17] [18]. \\
\hline IND16 & Marginalization $^{* *}$ & Marginalization index [21] [22]. \\
\hline IND17 & Social deprivation $^{* *}$ & Social deprivation index [23]. \\
\hline
\end{tabular}

*Population $\geq 20$ years of age; ${ }^{* *}$ Open population.

tion of the loads that the indicators have in the extracted components [24] [25]. For the processing and analysis the SPSS version 18 statistical program was used [26]. Subsequently, a confirmatory analysis with multivariate technique (SEM) was developed to evaluate the described model for the PCA results. The development of the model was carried out in the Amos software version 20.

A sequence diagram was constructed to facilitate the design of casual relations and the relation between the components and indicators, parting from this, the model was created. The three components extracted in the PCA, became non-observable latent variables and the MDMT2 became the endogenous variable, in the structural model. The measurement model was specified to indicate the indicators each component.

The sample was of 116 and the model included 23 non-observable variables (three components and 20 estimated measuring errors), therefore, it was complied with what was recommended, at least five observations per estimated parameter [25].

As entry data, the correlations matrix was used, and for the estimate of the model the maximum likelihood technique was applied and the direct estimation process. The procedure was carried out 14 times to estimate the maximum likelihood and to find the best possible adjustment.

The infringing estimates were validated, identifying three with a negative variance in the measuring error, so three constraints were added and these variances were fixed with a value of 0.005 [27] [28]. The validity of the model was done through the degrees of freedom, that according to condition and order, these must be higher of equal to zero [25].

To evaluate the overall fit of the model, the likelihood ratio chi-square statistic was examined, to measure the correspondence between the correlations matrix actual input or observed with that it is predicted by the proposed model. This indicator resulted too high in comparison with the degrees of freedom, which indicates that among the observed matrixes and those, estimated there is a significant difference, therefore this evaluation was completed with other fit measures [29]. 
The validation for the integral model was carried out as a whole in order to identify the degree in which the specified indicators represent the assumptions constructs, for that absolute fit measures, increasing and parsimony were used (Table 2) [25].

Finally, to evaluate the fit, the values obtained from the indexes were catalogued in accordance to the scale: low grade $(0.000-0.333)$, average $(0.334$ - 0667$)$ and high $(0.668-1.0)$; in accordance to results published by another study [33].

\section{Results}

As it is shown in Table 3, the rate for diabetes (MDMT2) showed a global decrease of 0.9 cases per 1000 habitants between 2005 and 2010, nevertheless, such decrease was higher in female population (0.6 cases/1000 hab.)

Table 2. Measures used to validate the integral model.

\begin{tabular}{|c|c|c|}
\hline Fit measures & Indicator & Values that show a good fit \\
\hline \multirow{2}{*}{ Absolute } & likelihood ratio chi-square statistic $\left(\mathrm{X}^{2}\right)$ [24] [25] & $\mathrm{p}>0.05[24]$ \\
\hline & Goodness of fit index (GFI) [24] [25] & $>0.90[24]$ \\
\hline \multirow{5}{*}{ Incremental } & Trucker-Lewis index (TLI) [25] & $>0.90[25]$ \\
\hline & Normed fit index (NFI) [24] [25] & $>0.90[24]$ \\
\hline & Relative fit index (RFI) [24] [30] & $>0.90[24]$ \\
\hline & Incremental fit index (IFI) [24] [31] & $>0.90[24]$ \\
\hline & Comparative fit index (CFI) [24] [32] & $>0.95[24]$ \\
\hline \multirow{3}{*}{ Parsimony } & Parsimonious normed fit index (PNFI) [24] [25] & $>0.50[24]$ \\
\hline & Parsimony goodness of fit index (PGFI) [25] & $>0.90[25]$ \\
\hline & Parsimonious comparative fit index (PCFI) [24] & $>0.50[24]$ \\
\hline
\end{tabular}

Table 3. State scenario of the used indicators. San Luis Potosí, México.

\begin{tabular}{|c|c|c|c|}
\hline \multirow{2}{*}{ Code } & \multirow{2}{*}{ Indicator name } & \multicolumn{2}{|c|}{ Year } \\
\hline & & 2005 & 2010 \\
\hline MDMT2* & Diabetes rate ${ }^{\mathrm{a}}$ & 8.7 & 7.8 \\
\hline IND1 $^{*}$ & Female Population $^{\mathrm{b}}$ & 53.0 & 52.5 \\
\hline IND2 $^{*}$ & Male population ${ }^{\mathrm{b}}$ & 47.0 & 47.5 \\
\hline IND3 & Ages $20-44^{\mathrm{b}}$ & 62.5 & 60.9 \\
\hline IND4 & Ages $45-49^{b}$ & 8.5 & 8.7 \\
\hline IND5 & Ages $50-59^{\mathrm{b}}$ & 12.4 & 13.3 \\
\hline IND6 & Ages $60-64^{\mathrm{b}}$ & 4.9 & 4.8 \\
\hline IND7 & Age 65 and older ${ }^{\mathrm{b}}$ & 11.7 & 12.3 \\
\hline IND8 $^{*}$ & Urban population $^{\mathrm{b}}$ & 64.8 & 65.6 \\
\hline IND9 $^{*}$ & Rural population ${ }^{\mathrm{b}}$ & 35.2 & 34.4 \\
\hline IND10 & Automobiles ${ }^{\mathrm{c}}$ & 12.0 & 17.1 \\
\hline IND11 & Homes with $\mathrm{TV}^{\mathrm{b}}$ & 86.2 & 88.0 \\
\hline IND12 $^{*}$ & Without secondary school $^{\mathrm{b}}$ & 2.7 & 2.9 \\
\hline IND13 $^{*}$ & Without health care ${ }^{\mathrm{b}}$ & 47.5 & 27.2 \\
\hline IND14 ${ }^{* *}$ & Income $^{\mathrm{b}}$ & 56.1 & 46.7 \\
\hline IND15* & Indigenous population $^{\mathrm{b}}$ & 11.0 & 10.7 \\
\hline IND16 $6^{* *}$ & Marginalization $^{\mathrm{d}}$ & high & high \\
\hline IND17 $7^{* *}$ & Social deprivation $^{\mathrm{d}}$ & high & high \\
\hline
\end{tabular}

"Population $\geq 20$ years; ${ }^{* *}$ Open population; ${ }^{\mathrm{a} R a t e}$ per every 1000 habitants; ${ }^{\mathrm{b}}$ Percentage; ${ }^{\mathrm{C}}$ for every 100 habitants; ${ }^{\mathrm{d}}$ Grade. 
that in the male population ( 0.3 cases/1000 hab.). at the same time, in the age group of 50 to 59 (IND5) there was also a decrease in the incidence rate of the illness (Table 3). On the other hand, some indicators, such as, urban population (IND8), percentage of homes with TV (IND11) and number of automobiles that are registered in circulation per every 100 habitants (IND10), increased in $0.8 \%, 1.8 \%$ and $5.1 \%$ respectably.

In Figure 2 it is shown a State scenario for MDMT2 where it can be seen that the tendency of the global rates were higher in the year 2005 than in 2010 in all the age groups, women had a higher rates than men did in the two time lapses analyzed; and in all the analyzed series the age group from 60 to 64 years, resulted with the highest rates.

The results of the tests of viability of PCA were as follows: a) Beginning with the Barlett sphericity test and the determinant from the correlations matrix was identified a high level of colineality among the analyzed variables (determinant $=1.23 \mathrm{E}-35$ ), presenting a significant difference in relation to the identity matrix $\left(\mathrm{Chi}^{2}=\right.$ 8722.03, $\mathrm{df}=136, \mathrm{p}=0.000)$; $\mathrm{b}$ ) with the Kaiser-Meyer-Olkin test $(\mathrm{KMO}=0.82)$, it was determined that the correlations are adequate to apply the PCA.

The male population indicator was removed from the analysis since it was in perfect correlation $(r=1)$ with the female population index and it was worked with a matrix of $17 \times 17$. In Table 4 shown the total variance explained by each component, achieving extract three components that explain the $96 \%$ of the accumulated variance the total data.

In Figure 3 can be observed that as of the fourth component, the slope is almost nonexistent, therefore only the three first components should be taken into account to represent the indicators group.

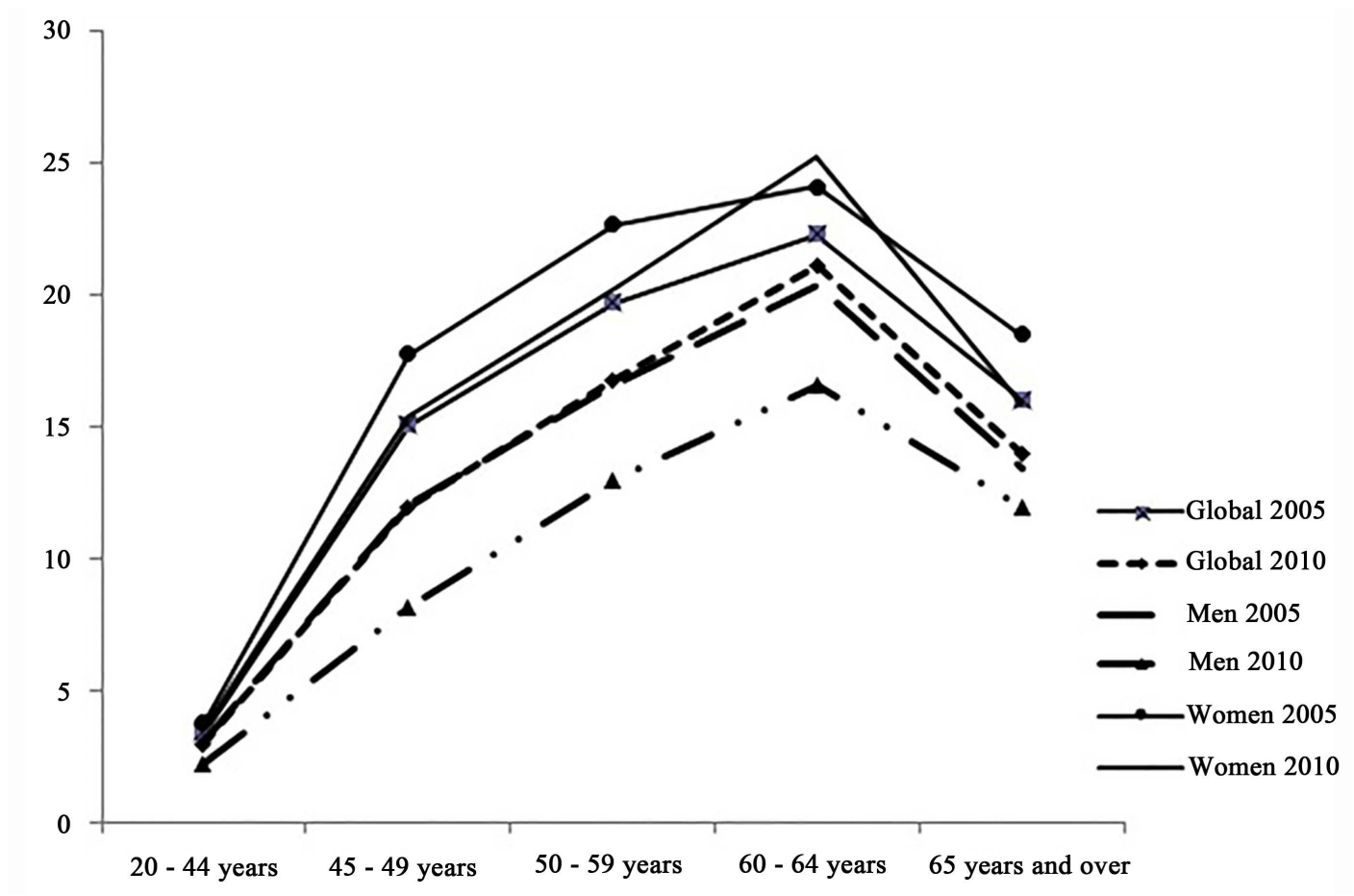

Figure 2. Rates of MDMT2 per every 1000 habitants $\geq 20$ years in the State of San Luis Potosí, México.

Table 4. Total variance explained by each component, of the variance of the original indicators.

\begin{tabular}{cccc}
\hline \multirow{2}{*}{ Component } & & Initial eigen-values & \\
\cline { 2 - 4 } & Total from the variance & \% from the variance & \% accumulated \\
\hline 1 & 12.718 & 74.810 & 74.810 \\
3 & 2.539 & 14.933 & 89.743 \\
& 1.070 & 6.297 & 96.039 \\
\hline
\end{tabular}




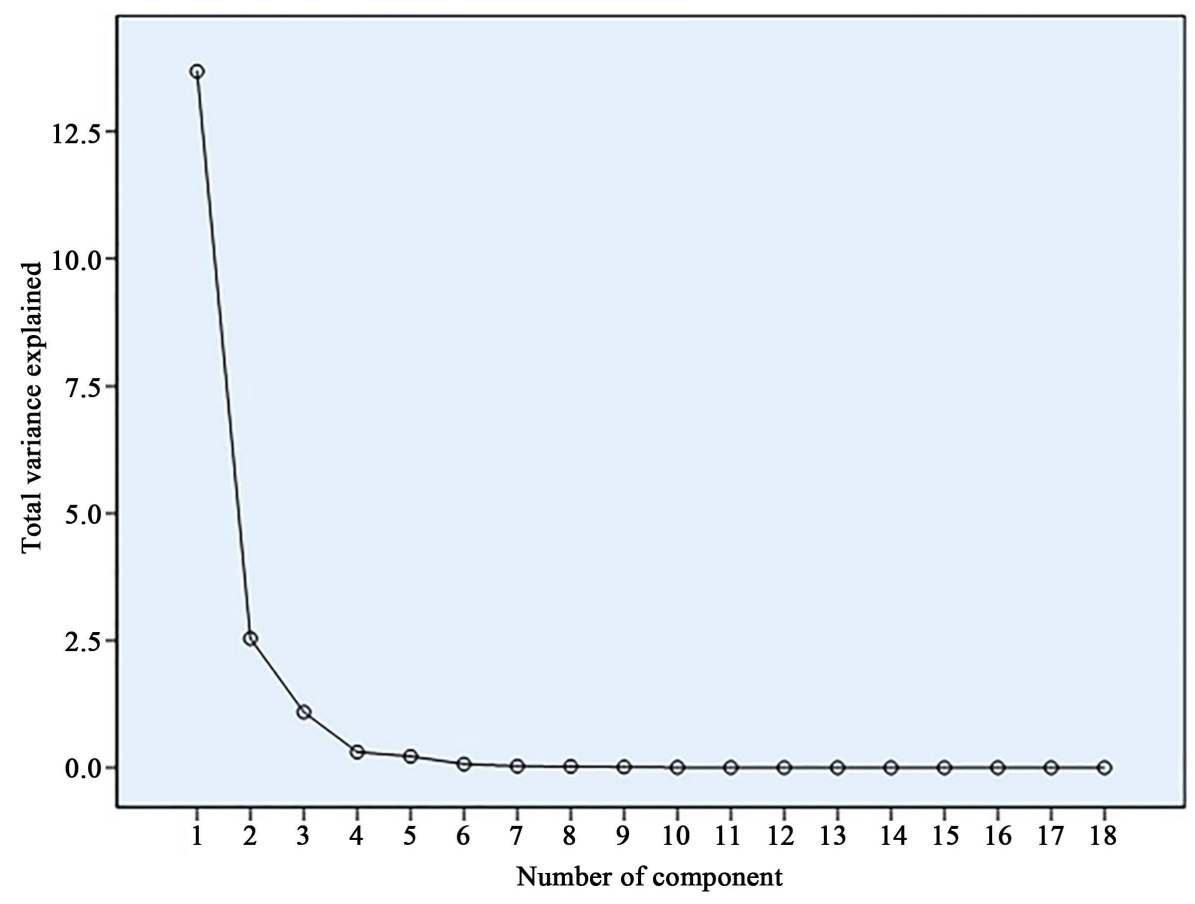

Figure 3. Sedimentation curve for the determination of the number of components extractable.

In Table 5, it is shown the matrix of rotated components by the varimax method which describes clearly the saturations of the indicators in each of the three components. According to this, the first component was formed by 11 indicators that on the whole explain $75 \%$ of the incidence rate evaluated in diabetes, being in order of importance in accordance to their multivariate correlations (attributed weights) the following: usage of automobiles (IND10 $=0.973$ ), age groups $45-49$ and $50-59$ (IND4 $=0.968$, IND5 $=0.965)$, urban population (IND8 = 0.965), female population (IND1 $=0.963)$ age group $60-64$ (IND6 $=0.962)$, homes with TV (IND11 $=0.962)$, age groups $20-44$ and 65 years or older (IND3=0.959, IND7 $=0.953$ respectably), population without health care (IND13 $=0.929)$ and population without secondary school (IND12 $=0.923)$. In the second component, with a level of attribution to the illness of $15 \%$ the following indicators were identified: High marginalization (IND16 $=0.924)$, Social deprivation (IND17 $=0.918)$ and low income (IND14 $=0.857)$, whereas in the third component with a level of attribution of a barely $6 \%$, the indicators included were: rural population (IND9 $=0.902$ ) and indigenous population (IND15 $=0.847$ ).

On the other hand, the confirmatory model was formed with 40 variables, 17 observable and 23 non-observable; 20 endogenous variables and 20 exogenous; and 133 degrees of freedom.

Figure 4 shows the integral model, the measuring errors $(\mathrm{e} 1, \ldots \mathrm{e} 20)$, the weights of the standardized regression coefficients for each indicator and the effects of the components on MDMT2.

According to the results of the structural model, the indicators of the first component represent a risk factor for MDMT2, since, for every increase of one unit in the first component; the diabetes increase rate will suffer an increase of 0.92 units, considering the synergy among the 11 indicators and their respective measuring error.

On the other hand, the indicators of the second and third component showed a very poor effect on MDMT2, showing for each unit increase in the second and third component, increased diabetes incidence rate of 0.02 and 0.01 units, respectively.

In Table 6 it is shown the statistical values that were used to assess model fit.

\section{Discussion}

Being diabetes a multifactorial illness, it is of great importance to study it and analyze it through multivariate models that allow us to know the load of the factors that determine it, since the methods that have been used do not allow us to face it adequately [34]. The PCA placed the official available indicators considered in the study, in three components in accordance to the multiple correlations among them, it also identified that the indicators 


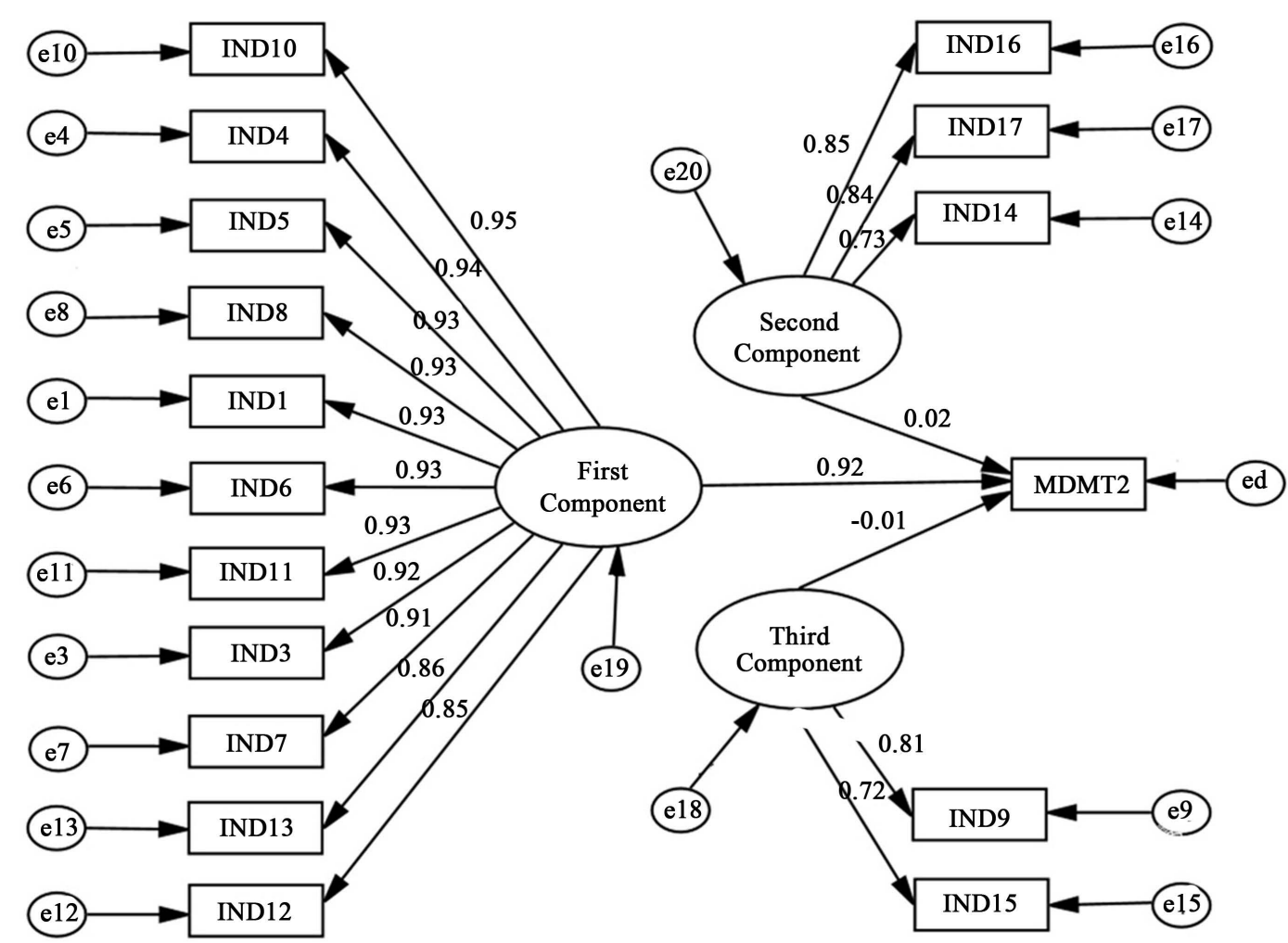

Figure 4. Structural model of the multivariate relations between MDMT2 and its social and environmental determinants obtained from SEM.

Table 5. Rotated component matrix by the Varimax method from PCA that shows the saturations (correlations) for each evaluated indicator in the different components extracted.

\begin{tabular}{cccc}
\hline & Name of the indicator & & Component \\
\cline { 3 - 4 } Code & Automobiles & 1 & 2 \\
\hline IND10 & Age 45 - 49 & 0.973 & \\
IND4 & Age 50 - 59 & 0.968 & \\
IND5 & Urban population & 0.965 & \\
IND8 & Female population & 0.965 & \\
IND1 & Age 60 - 64 & 0.963 & \\
IND6 & Homes with TV & 0.962 & \\
IND11 & Age 20 - 44 & 0.962 & \\
IND3 & Age 65 and older & 0.959 & \\
IND7 & Without health care & 0.953 & \\
IND13 & Without secondary school & 0.929 & \\
IND12 & Marginalization & 0.923 & -0.259 \\
IND16 & Social deprivation & -0.298 & 0.924 \\
IND17 & Income & & 0.918 \\
IND14 & Rural population & -0.338 & 0.857 \\
IND9 & Indigenous population & 0.257 & 0.327 \\
IND15 & & & 0.902 \\
\hline
\end{tabular}


Table 6. Validation indicators of integral model fit.

\begin{tabular}{|c|c|c|c|c|c|}
\hline \multirow{2}{*}{ Fit measures } & \multirow{2}{*}{ Indicator } & \multirow{2}{*}{ Value } & \multicolumn{3}{|c|}{ Grade } \\
\hline & & & Low & Average & High \\
\hline \multirow{2}{*}{ absolute } & Chi-square authenticity ratio & 3367.6 (133 df) & $\mathrm{X}$ & & \\
\hline & GFI & 0.298 & $\mathrm{X}$ & & \\
\hline \multirow{5}{*}{ incremental } & TLI & 0.637 & & $\mathrm{X}$ & \\
\hline & NFI & 0.636 & & $\mathrm{X}$ & \\
\hline & RFI & 0.628 & & $\mathrm{X}$ & \\
\hline & IFI & 0.645 & & $\mathrm{X}$ & \\
\hline & CFI & 0.645 & & $\mathrm{X}$ & \\
\hline \multirow{3}{*}{ parsimony } & PNFI & 0.622 & & $\mathrm{X}$ & \\
\hline & PGFI & 0.259 & $\mathrm{X}$ & & \\
\hline & PCFI & 0.631 & & $X$ & \\
\hline
\end{tabular}

GFI: Goodness of fit index; TLI: Trucker-Lewis index; NFI: Normed fit index; RFI: Relative fit index; IFI: Incremental fit index; CFI: Comparative fit index; PNFI: Parsimonious normed fit index; PGFI: Parsimony goodness of fit index; PCFI: Parsimonious comparative fit index.

of the first component have a high correlation with diabetes, whereas the second and third have little.

The first component explains almost $75 \%$ of the total variance, the order of the indicators that make it up in accordance to the correlations coefficient multivariate is: automobiles in circulation, the different age groups, urban population, female population, homes with TV, population without health care and without secondary school studies; these indicators can be attributed them the greatest percentage of weight in the incidence rates for diabetes mellitus type 2, while the ones in the second component (marginalization, social depravation, income) and third component (rural population and indigenous population) can be attributed little weight.

This is confirmed by the structural model, that shows the hierarchy of the components in accordance to the effect that they have on MDMT2 and on that of the indicators, based on the weight that it represents over their respective component, thus, the ones in the first component (effect $=0.92$ ) are the most important ones. The second and third components have an effect of 0.02 and -0.01 respectably over MDMT2 which it is not significant, therefore the indicators that conform it are not very relevant for the illness, nevertheless, Kuhmbou [6] and Dinca-Panaitescu and col [7] reported that a low income was in relation with high levels of diabetes, non the less this authors used lineal regression methods and logistics that may only evaluate casual lineal relations, whereas in the present study multivariate relations were analyzed of the different factors simultaneously, considering the measuring error.

Different studies confirm the associations that the model identified, but on a lineal manner, the results of this study are in accordance in an indirect way with those of Bener and Col [8] and Escolar [11], who reported that obesity is a risk factor for the development of the illness; on the other hand, the time that the population spends in the car is an indicator of obesity [35], in this study it was estimated in an indirect way, through the number of automobiles that are registered in circulation, this indicator resulted as a risk factor as well. Also, a relation was found between diabetes and the age; in other studies this relation was also identified [6] [8]-[10]. Another finding was that living in an urban area is also a risk factor, which also coincides with other reported results [6] [9].

Also, it was identified that being a female is a risk factor to suffer diabetes, which also coincides with other studies [7] [10]. It was also identified as a risk factor the time that the population watches television; this was estimated through the number of habited houses that have a TV, this coincides indirectly with other studies [12].

Bener and Col [8] published that a low educational level is a risk factor, in this study a similar result was obtained, and it was also found that not having health care in public institutions is a risk factor, this coincides with what was published by the PAHO [4].

In the analysis, some indicators were not considered which are relevant, as determinants of MDMT2, since official sources do not have a register on these. According to the theoretical model taken as a base for this study (Figure 1), the following risk factors were not included: overweight and obesity [4] [5] [11] [35] family diabetes 
background [5] [8], nutritional aspects such as diet type, number of meal per day and their schedules [4] [5], time spent in: physical activities [4] [5] [8], watching television [12] and the use of computers [4] [5] [36].

In future investigations it would be important to consider all of these indicators in order to achieve a more complete analysis and improve decision making, it is possible that when included in the analysis, some of the ones placed in the first component would be moved to another component of lesser importance.

According to the 2012 ENSANUT, in the State of San Luis Potosi, from 2006 to 2012 there was an increase of $3.8 \%$ in diabetes mellitus prevalence in adults $\geq 20$ years [37], which demonstrates that the prevention and control strategies for the illness must improve. At the same time, the program for prevention and control for diabetes that is currently at work in the state [38], focuses its actions in adults $\geq 20$ in general, therefore the integral results obtained in the study may be used to sustain strategies that would improve the different national programs for the prevention and control of DMT2 [38] [39].

\section{Conclusions}

The structural model shows its utility for the evaluation and hierarchy of the social and environmental determinants for MDMT2; this information may sustain the design of strategies and public policies for the prevention and control of the illness, which have to be directed mainly to the factors which integrate the first component, considering as well the order of importance of such factors to the interior of the same component according to their level of attribution with such illness, besides being planned and carried out taking into account in a holistic way all of these factors. On the other hand, the health system should have a database of all the indicators related to diabetes in order to carry out complete integrals analysis and improve decision making.

Finally, we consider it important to emphasize in the necessity of to work, in the design of indicators that allow us to incorporate aspects related to nutritional habits of the population at risk, to achieve assess their levels of attribution in the high rates of diabetes. Currently it does not have this information.

\section{References}

[1] World Health Organization (2012) Diabetes. Data and Numbers. Descriptive Note 312. http://www.who.int/mediacentre/factsheets/fs312/es/

[2] International Diabetes Federation (2014) IDF Diabetes Atlas. 6th Edition. http://www.idf.org/diabetesatlas

[3] Hernández, M., Gutiérrez, J.P. and Reynoso-Noverón, N. (2013) Diabetes Mellitus in México. The State of the Outbreak. Public Health in Mexico, 55, 120-136. http://bvs.insp.mx/rsp/articulos/articulo.php?id=002844

[4] Pan American Health Organization (2007) Regional Strategy and Action Plan for an Integrated Approach on the Prevention and Control of Chronicle Diseases. http://www.msal.gov.ar/argentina-saludable/pdf/reg-strat-cncds.pdf

[5] International Diabetes Federation (2013) Risk Factors. http://www.idf.org/worlddiabetesday/toolkit/es/gp/factores-de-riesgo

[6] Kuhmbou, W. (2013) The Escalating Diabetes Epidemic: Determinants of Prevalence Disparity between Country Income Groups. Master Thesis, University of Tromso, Noruega. http://munin.uit.no/bitstream/handle/10037/5201/thesis.pdf?sequence=2

[7] Dinca-Panaitescu, S., Dinca-Panaitescu, M., Bryant, T., Daiski, I., Pilkington, B. and Raphael, D. (2011) Diabetes Prevalence and Income: Results of the Canadian Community Health Survey. Health Policy, 99, 116-123.

http://www.ncbi.nlm.nih.gov/pubmed/20724018 http://dx.doi.org/10.1016/j.healthpol.2010.07.018

[8] Bener, A., Zirie, M., Ibrahim, M., Janahi, I.M., Al-Hamaq, A., Musallam, M. and Wareham, N.J. (2009) Prevalence of Diagnosed and Undiagnosed Diabetes Mellitus and Its Risk Factors in a Population-Based Study of Qatar. Diabetes Research and Clinical Practice, 84, 99-106. http://www.ncbi.nlm.nih.gov/pubmed/19261345 http://dx.doi.org/10.1016/j.diabres.2009.02.003

[9] Hu, D., Sun, L., Fu, P., Xie, J., Lu, J., Zhou, J., Yu, D., Whelton, P., He, J. and Gu, D. (2009) Prevalence and Risk Factors for Type 2 Diabetes Mellitus in the Chinese Adult Population: The InterASIA Study. Diabetes Research and Clinical Practice, 84, 288-295. http://www.ncbi.nlm.nih.gov/pubmed/19442859 http://dx.doi.org/10.1016/j.diabres.2009.02.021

[10] Deo, S., Zantye, A., Mokal, R., Mithbawkar, S., Rane, S. and Takur, K. (2006) To Identify the Risk Factors for High Prevalence of Diabetes and Impaired Glucose Tolerance in Indian Rural Population. International Journal of Diabetes in Developing Countries, 26, 19-23. http://www.rssdi.in/diabetesbulletin/2006/Jan/IntJDiabDevCtries26119-2619419_071634.pdf 
http://dx.doi.org/10.4103/0973-3930.26886

[11] Escolar, A. (2009) Social Determiners Facing Life Styles in Diabetes Mellitus Type 2 in Andalucía: The Difficulty to Make Ends Meet or Obesity? Gaceta Sanitaria, 23, 427-432. http://dx.doi.org/10.1016/j.gaceta.2008.12.005

[12] Hu, F.B., Li, T.Y., Colditz, G.A., Willett, W.C. and Manson, J.E. (2003) Television Watching and Other Sedentary Behaviors in Relation to Risk of Obesity and Type 2 Diabetes Mellitus in Women. Journal of the American Medical Association, 289, 1785-1791. http://dx.doi.org/10.1001/jama.289.14.1785

[13] González, M.T. and Landero, R. (2008) Confirmation of an Explicative Model of Stress and of the Psychosomatic Symptoms through Structural Equations. Revista Panamericana de Salud Pública, 23, 7-18. http://www.scielosp.org/pdf/rpsp/v23n1/a02v23n1

[14] Oliver, A., Navarro, E., Meléndez, J.C., Molina, C. and Tomás, J.M. (2009) Structural Equations Model to Predict the Wellbeing and Functional Dependence on Elderly People in the Dominican Republic. Revista Panamericana de Salud Pública, 26, 189-196. http://www.scielosp.org/pdf/rpsp/v26n3/01.pdf

[15] San Luis Potosí State Government. México (2013) Foreign Affairs Bureau. http://www.sre.gob.mx/coordinacionpolitica/images/stories/documentos_gobiernos/pestatalslp.pdf

[16] Health Services in the State of San Luis Potosí. México (2012) Unique Information System for Epidemiological Surveillance (SUIVE-2007).

[17] National Institute for Statistics and Geography. México (2013) Time Series. Dataset: Total Population and 5 Years and Over by Demographic and Social Characteristics. http://www.inegi.org.mx/sistemas/olap/Proyectos/bd/censos/comparativo/PDS.asp?s=est\&c=17161\&proy=sh_pty5ds

[18] National Institute for Statistics and Geography. México (2011) Data Base on Population and Homes. Population and House Count. Population and Homes Census 2010. http://www3.inegi.org.mx/sistemas/tabuladosbasicos/default.aspx?c=27302\&s=est

[19] National Institute for Statistics and Geography. México (2011) Data Base for Registered Automobiles on the Road. http://www3.inegi.org.mx/sistemas/biinegi/default.aspx

[20] National Health Information System. México (2012) Population Estimates CONAPO-COLMEX. Coverage Data Base on Health Services. http://www.sinais.salud.gob.mx/basesdedatos/index.html

[21] National Population Council. México (2012) Data Base on Marginalization Indexes by Counties, 2005. http://www.conapo.gob.mx/es/CONAPO/Indices_de_marginacion_2005

[22] National Population Council. México (2012) Data Base on Marginalization Indexes by Counties, 2010. http://www.conapo.gob.mx/es/CONAPO/Indices_de_Marginacion_2010_por_entidad_federativa_y_municipio

[23] National Council for Evaluation of Social Development Policies. México (2012) Data Base on Marginalization Indexes for Federal Entities and Counties 2005 and 2010. Excel for States and Municipalities. http://www.coneval.gob.mx/Medicion/Paginas/\%c3\%8dndice-de-Rezago-social-2010.aspx

[24] Meyers, L.S., Gamst, G. and Guarino, A.J. (2006) Applied Multivariate Research. Design and Interpretation. SAGE Publications, Thousand Oaks.

[25] Hair, J., Anderson, R., Tatham, R. and Black, W. (2007) Multivariate Analysis. 5th Edition, Prentice-Hall, Madrid.

[26] Carver, R. and Nash, J. (2011) Doing Data Analysis. With SPSS Version 18. Cengage Learning, E.U.A. http://dl.acm.org/citation.cfm?id=1983473

[27] Bentler, P.M. and Chou, C. (1987) Practical Issues in Structural Modeling. Sociological Methods and Research, 16, 78117. http://dx.doi.org/10.1177/0049124187016001004

[28] Dillon, W., Kumar, A. and Mulani, N. (1987) Offending Estimates in Covariance Structure Analysis-Comments on the Causes and Solutions to Heywood Cases. Psychological Bulletin, 101, 126-135.

http://psycnet.apa.org/index.cfm?fa=buy.optionToBuy\&id=1987-14504-001 http://dx.doi.org/10.1037/0033-2909.101.1.126

[29] Green, S.B., Akey, T.M., Fleming, K.K., Hershberger, S.C. and Marquis, J.G. (1997) Effect of the Number of Scale Points of Chi-Square Fit Indices in Confirmatory Factor Analysis. Structural Equation Modeling, 4, 108-120. http://dx.doi.org/10.1080/10705519709540064

[30] Widaman, K.F. and Thompson J.S. (2003) On Specifying the Null Model for Incremental Fit Indices in Structural Equation Modeling. Psychological Methods, 8, 16-37. http://dx.doi.org/10.1037/1082-989X.8.1.16

[31] Bollen, K.A. (1989) A New Incremental Fit Index for General Structural Equation Models. Sociological Methods and Research, 17, 303-316. http://dx.doi.org/10.1177/0049124189017003004

[32] Bentler, P.M. (1990) Comparative Fit Indexes in Structural Models. Psychological Bulletin, 107, $238-246$. http://www.uri.edu/research/cprc/Publications/PDFs/ByTitle/Comparative\%20Fit\%20Indexes\%20in\%20Structural\%20 Models.pdf 
http://dx.doi.org/10.1037/0033-2909.107.2.238

[33] Rodríguez, J. (2006) Validation for the Consumer's Psycoeconomic model. Causative Analysis with Structural Equations. Thought and Management, 20, 1-54. http://www.redalyc.org/pdf/646/64602001.pdf

[34] Muñoz, J.M. (2011) Overweight, Obesity and Diabetes: Several Approaches for Its Study. Julián Manzur Ocaña Collection. Autonomous Juarez University of Tabasco, Villahermosa.

[35] Jacobson, S.H., King, D.M. and Yuan, R. (2011) A Note on the Relationship between Obesity and Driving. Transport Policy, 18, 772-776. http://dx.doi.org/10.1016/j.tranpol.2011.03.008

[36] Schaller, N., Seiler, H., Himmerich, S., Karg, G., Gedrich, K., Wolfram, G. and Linseisen, J. (2005) Estimated Physical Activity in Bavaria, Germany, and Its Implications for Obesity Risk: Results from the BVS-II Study. International Journal of Behavioral Nutrition and Physical Activity, 2, 6. http://dx.doi.org/10.1186/1479-5868-2-6

[37] Public Health National Institute, México (2013) National Survey on Health and Nutrition 2012. Results by Federal Entity. http://ensanut.insp.mx/informes/SanLuisPotosi-OCT.pdf

[38] State Government of San Luis Potosí. México (2013) Health Services in the State of San Luis Potosí. http://www.slpsalud.gob.mx/programas.html

[39] Government of the Mexican Republic. México (2013) National Strategy for the Control and Prevention of Overweight, Obesity and Diabetes. http://promocion.salud.gob.mx/dgps/descargas1/estrategia/Estrategia con portada.pdf 
Scientific Research Publishing (SCIRP) is one of the largest Open Access journal publishers. It is currently publishing more than 200 open access, online, peer-reviewed journals covering a wide range of academic disciplines. SCIRP serves the worldwide academic communities and contributes to the progress and application of science with its publication.

Other selected journals from SCIRP are listed as below. Submit your manuscript to us via either submit@scirp.org or Online Submission Portal.
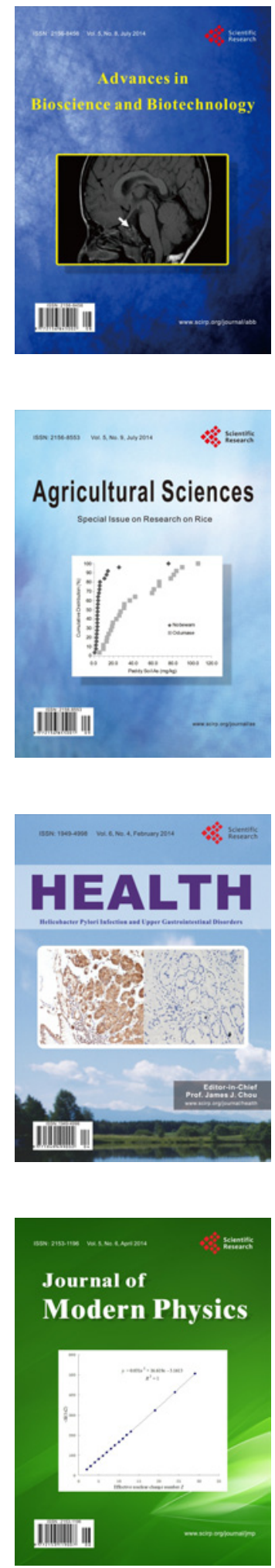
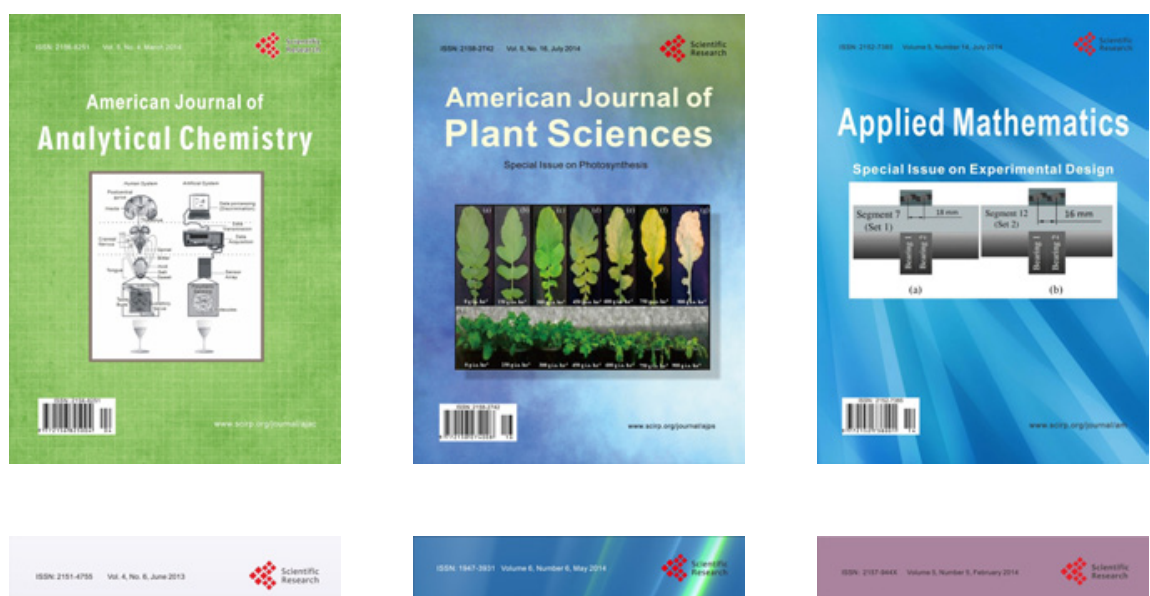

Creative Education
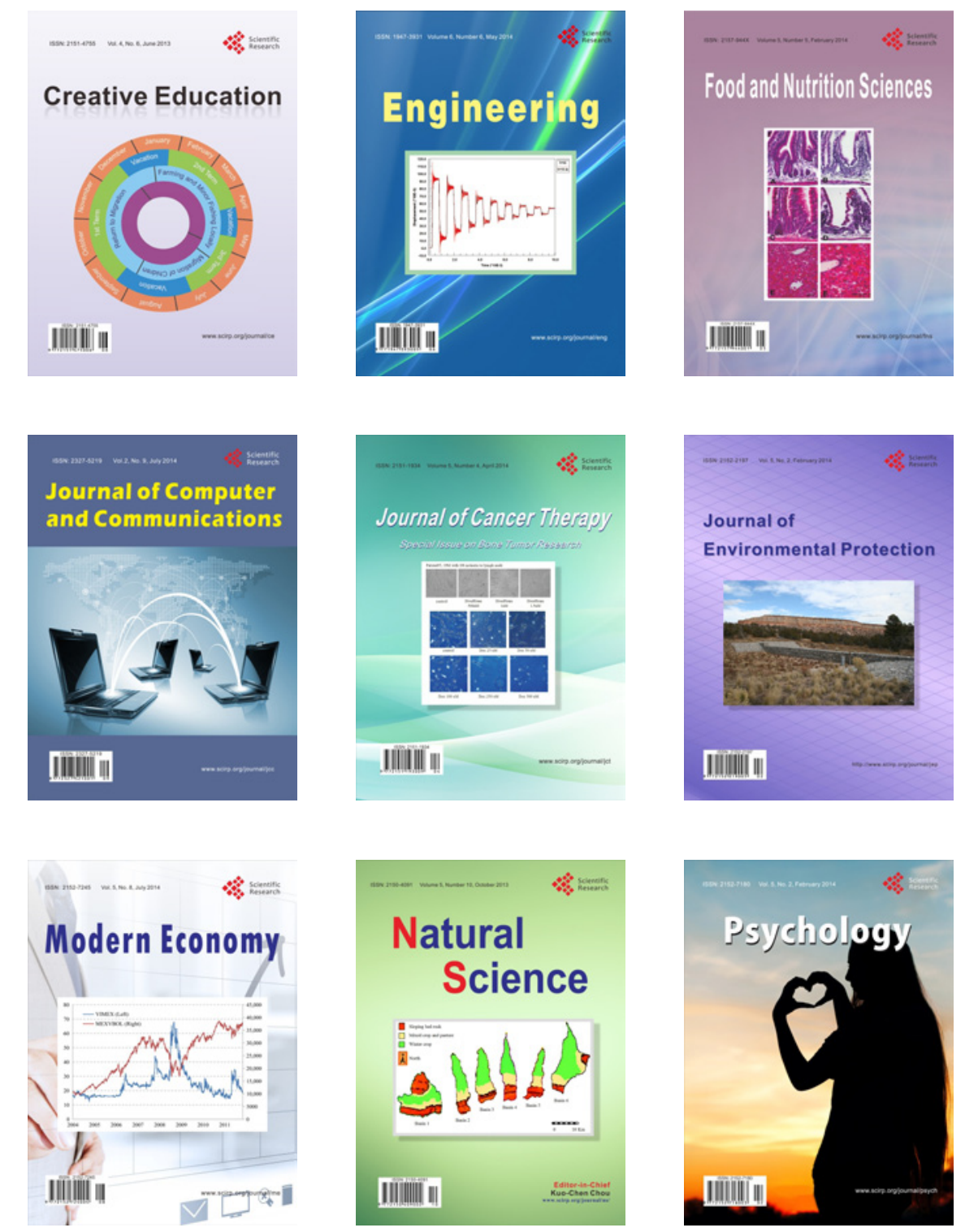